\title{
Surveillance of communicable disease from a tertiary care teaching hospital of central Kerala, India
}

\section{Velikkakath Divakaran Manjula, Anitha Bhaskar, Akshayakumar Sobha}

Department of Community Medicine, Government Medical College, Kottayam, Kerala, India

Address for the Correspondence: Dr. V. D. Manjula, Government Medical College, Kottayam, Kerala, India.

E-mail: vdmanju@gmail.com

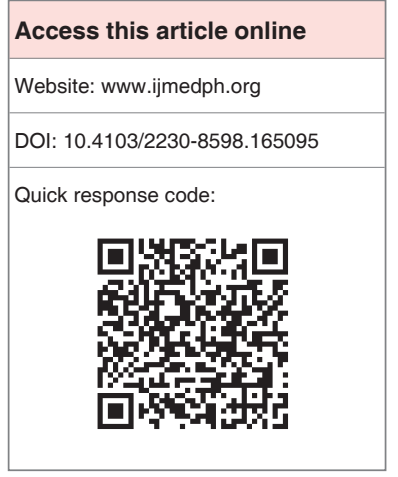

Background: Surveillance is the back bone of any disease control program. Communicable disease is a major cause of morbidity. Precise data on the pattern of communicable disease will enable us to identify the epidemic early so that timely response will be possible. Aims: (1) To find out the morbidity and mortality pattern of communicable diseases. (2) To study the disease trend and seasonality of acute respiratory infections (ARIs) and acute diarrheal diseases (ADD). Materials and Methods: Retrospective record-based descriptive study was done to find out the morbidity and mortality pattern of communicable disease and trend of seasonality. Five years surveillance data from 2009 to 2013 were collected and analyzed. Results: Maximum morbidity (47.6\%) was observed in air borne diseases. ARI accounted for $53 \%$, and pulmonary tuberculosis $27 \%$ of morbidity among air borne diseases. Admissions from water borne diseases were mainly done for ADD $(47 \%)$, followed by hepatitis (34\%). $90 \%$ of the morbidity from vector borne disease was due to dengue fever. ADD showed a rise during the summer season, and ARI showed peak during the rainy season. The difference in incidence observed between seasons for ADD and ARI were statistically significant $(P=0.001)$. Leptospirosis and chickenpox were present throughout the years. Increase in mortality from all communicable diseases was observed from the year 2011 onwards. $48 \%$ of mortality was due to air borne diseases such as pulmonary tuberculosis, pneumonia, and chickenpox. Conclusion: Maximum morbidity and mortality were due to airborne diseases. Incidence of ADD was more during the summer while ARI was more during the rainy season.

Key words: Air borne diseases, communicable diseases, seasonal trend, surveillance, vector borne diseases, water borne diseases

\section{INTRODUCTION}

Communicable disease is an illness due to a specific infectious agent or its toxic products capable of being directly or indirectly transmitted from man to man, animal to animal or from the environment (through air, dust, soil, water, food etc.) to man or animal. ${ }^{[1]}$ Communicable disease have been classified into five major groups namely vehicle borne, vector borne, air borne, fomite borne and diseases transmitted by unclean hands and fingers. In the year 1995, World Health Assembly urged all the 191 member countries to strengthen surveillance of infectious diseases in order to detect reemerging infection promptly, identifying emerging infections and to respond more appropriately to both epidemic and endemic infectious diseases. ${ }^{[2]}$ India launched the National Surveillance Program for Communicable diseases during 1997-1998 with the objective of early detection and timely response to outbreaks of communicable disease. ${ }^{[3]}$

Analysis of the data of communicable disease will identify the changing trends of morbidity and mortality due to the same in our state. Hence, an observational retrospective study was conducted in the tertiary care teaching hospital. State prevention of epidemic and infectious disease cell (SPEID cell) was established by Government of Kerala in 1982 in Medical College Hospital Thriuvananthapuram with a view to strengthen the surveillance system of communicable diseases in the state. As part of strengthening of SPEID cell regional prevention of epidemic and infectious disease cell (RPEID) cells 
were also established in Community Medicine Departments of all Government Medical Colleges in 1989. ${ }^{[4]}$ However, at the inception of RPEID cell, surveillance data on communicable disease pertaining to medical colleges were sent to SPEID cell on a weekly basis, which was in turn made available to the health services. However, the reporting was not complete and timely because it was passive by the respective departments. However, after implementation of the integrated disease surveillance program (IDSP), surveillance was further strengthened by posting data entry operator who will actively collect and sent the data daily to the respective district surveillance unit of district medical officer of health and SPEID cell via E-mail. Thus, the quality of data has been improved in terms of completeness and timeliness.

The present study was conducted in the tertiary care teaching hospital of central Kerala at government sector, which is a referral center for neighboring districts. A retrospective study was planned to find out the morbidity and mortality pattern of communicable diseases and to study the seasonality of acute respiratory infection (ARI) and acute diarrhoeal diseases (ADD).

\section{MATERIALS AND METHODS}

The RPEID cell is the nodal unit of surveillance of communicable disease in medical college. The associate professor of Community Medicine Department is the coordinator of RPEID cell. The data entry operator of the RPEID cell will collect the data on communicable diseases admitted as an inpatient in the medical wards, which will be cross checked by a junior resident and verified by the coordinator in the department. Any disparity of data or confusion in diagnosis will be cleared by discussing with the consultants in the respective units then and there. The surveillance data thus collected for a period of 5 years from 2009 to 2013 were taken from the records of RPEID cell to identify the pattern of morbidity and mortality from various communicable diseases and its trend of seasonality. In IDSP, we report all communicable diseases either as laboratory confirmed or as probable cases. In the present study we have classified disease into the three major groups of laboratory confirmed disease namely air borne, water borne and vector borne. All the probable cases and diseases with less numbers were categorized into "other" group. The data were analyzed in excel, and frequency of communicable diseases were computed. ARI and ADD cases were analyzed according to seasons such as summer (March-June), rainy (July-October) and winter (November-February). Differences in frequency between two sample proportions (between seasons) were tested using $Z$ test. $P<0.05$ was fixed as a significant level.

\section{RESULTS}

The surveillance data revealed that a total of 26,981 patients were admitted with various communicable diseases in the hospital during the year 2009-2013. Communicable diseases were categorized as vector borne disease, water borne disease, air borne disease (confirmed cases) and others. Others comprised of probable cases of dengue, leptospirosis, and enteric fever, pyrexia of unknown origin and blood borne diseases such as hepatitis B and hepatitis C [Table 1]. Morbidity due to air borne disease was constituted by $47.6 \%$, followed by water borne diseases (14.6\%) and least by vector borne disease. Considering the general trend of various communicable diseases, it was seen that vector borne disease is in the rise while water borne disease is decreasing. Air borne disease showed higher proportion when compared to vector borne disease but from 2012 onwards it is showing a decreasing trend. Up to 2012 water borne disease was higher than vector borne disease but by 2013 the vector borne disease had overcome the water borne disease [Table 1].

Among the air borne diseases, ARI was in the top position (53.14\%), followed by pulmonary tuberculosis (27.44\%) [Table 2].

\begin{tabular}{|c|c|c|c|c|c|c|}
\hline Disease & 2009 & 2010 & 2011 & 2012 & 2013 & Total number \\
\hline Vector borne & $152(6.6)$ & $264(11.4)$ & $124(5.4)$ & 567 (24.5) & $1204(52.1)$ & $2311(8.6)$ \\
\hline Water borne & $1037(26.4)$ & $853(21.7)$ & $903(23)$ & 687 (17.5) & $448(11.4)$ & $3928(14.6)$ \\
\hline Air borne & 1607 (12.5) & 3434 (26.7) & $2681(20.8)$ & 2991 (23.3) & $2148(16.7)$ & $12861(47.6)$ \\
\hline Others & $1109(14.1)$ & 1481 (18.8) & $1450(18.4)$ & $1837(23.3)$ & $2004(25.4)$ & $7881(29.2)$ \\
\hline Total & 3905 (14.5) & $6032(22.4)$ & $5158(19.1)$ & $6082(22.5)$ & $5804(21.5)$ & $26981(100)$ \\
\hline
\end{tabular}

Figure in parentheses shows the percentage

\begin{tabular}{|c|c|c|c|c|c|c|}
\hline Diseases & 2009 & 2010 & 2011 & 2012 & 2013 & Total number \\
\hline ARI & $952(13.9)$ & $1904(27.9)$ & 1061 (15.5) & $1623(23.7)$ & 1294 (19) & $6834(53.14)$ \\
\hline Tuberculosis & $63(1.8)$ & $749(21.2)$ & $1077(30.5)$ & $1057(30)$ & $583(16.5)$ & $3529(27.44)$ \\
\hline Pneumonia & $267(24)$ & $391(35.2)$ & $196(17.6)$ & $138(12.4)$ & $119(10.8)$ & $1111(8.64)$ \\
\hline Chicken pox & $145(20.5)$ & $138(19.5)$ & $181(25.6)$ & $121(17.1)$ & $123(17.3)$ & $708(5.51)$ \\
\hline Measles & $37(11.8)$ & $142(45.4)$ & $119(38)$ & $5(1.6)$ & $10(3.2)$ & $313(2.43)$ \\
\hline Mumps & $27(28.5)$ & $14(14.7)$ & 12 (12.6) & $31(32.6)$ & $11(11.6)$ & $95(0.74)$ \\
\hline Meningitis & $109(45.6)$ & 81 (33.9) & $32(13.4)$ & $9(3.8)$ & $8(3.3)$ & $239(1.86)$ \\
\hline Others & 7 (21.9) & $15(46.9)$ & $3(9.4)$ & $7(21.8)$ & $0(0)$ & $32(0.25)$ \\
\hline Total & $1607(12.5)$ & $3434(26.7)$ & $2681(20.8)$ & $2991(23.3)$ & 2148 (16.7) & $12,861(100)$ \\
\hline
\end{tabular}

Figure in parentheses shows the percentage, $A R I=$ Acute respiratory infections 
Pattern of water borne disease showed that the major contribution was from ADD (47\%), followed by hepatitis (34\%). Leptospirosis is a public health problem in our area with a constant proportion [Table 3].

Majority (89.8\%) of vector borne disease was constituted by dengue followed by malaria $(9.1 \%)$. The proportion of dengue was drastically increased from 2012 onwards. Others include chikungunya and Japanese encephalitis, which is $1.1 \%$ only [Table 4].

General trend of communicable disease showed that vector borne disease was on increase while waterborne disease was on decrease. Airborne disease also showed a decrease in trend [Graph 1].

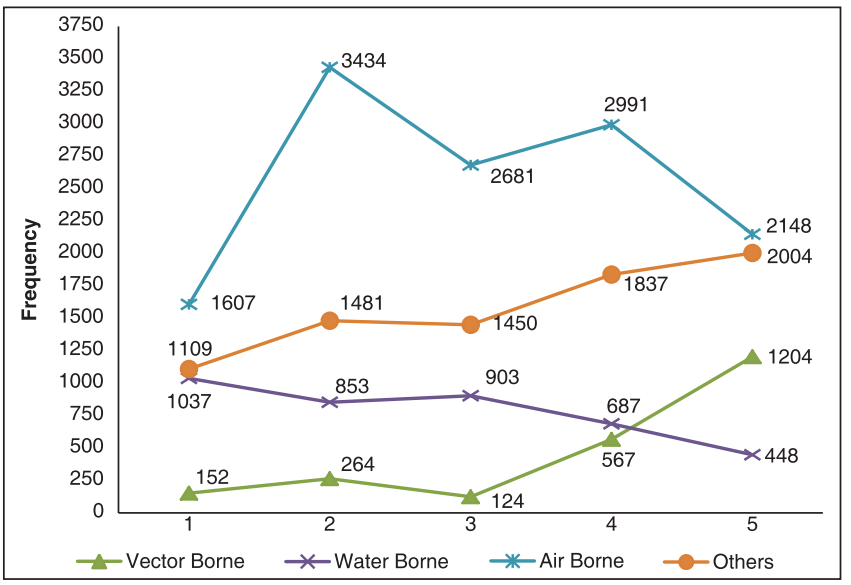

Graph 1: Communicable disease data 2009-2013
Among the air borne disease ARI showed a definite seasonal variation with rise in cases during the rainy season except for the year 2010 and 2013 [Graph 2]. When this observed difference in the proportion of ARI was compared between seasons, it was found to be significant [Table 5].

Considering the water borne diseases, ADD showed a seasonal peak during the summer except in 2013 [Graph 3]. The difference in the occurrence of ADD in summer with rainy and winter season was statistically significant [Table 6].

During the study period, a total of 319 deaths due to communicable diseases were reported from our institution [Table 7].

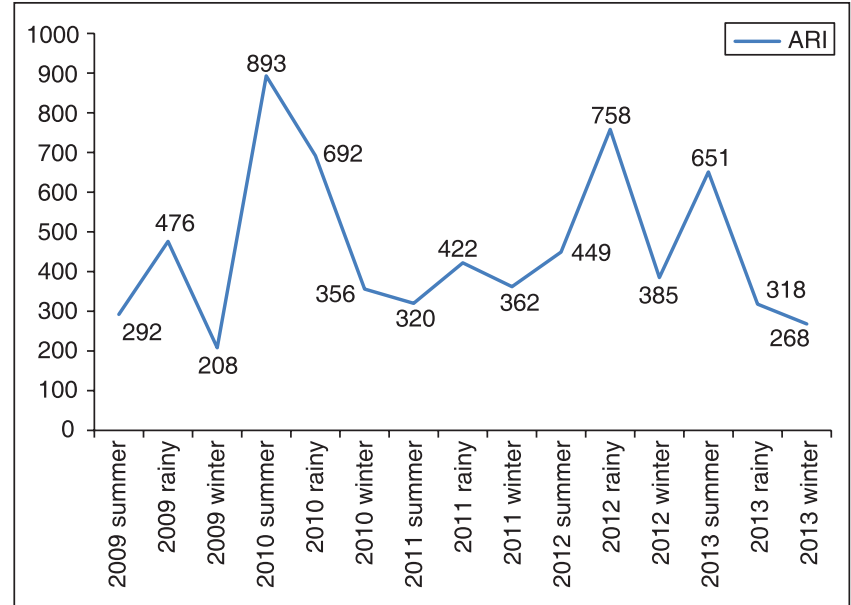

Graph 2: Seasonal variation of acute respiratory infections 2009-2013

\begin{tabular}{|c|c|c|c|c|c|c|}
\hline Diseases & 2009 & 2010 & 2011 & 2012 & 2013 & Total number \\
\hline ADD* & 467 (25.3) & $468(25.4)$ & $379(20.5)$ & $270(14.6)$ & $262(14.2)$ & $1846(47)$ \\
\hline Viral hepatitis & 373 (27.9) & 276 (20.6) & $338(25.2)$ & $255(19.1)$ & $97(7.2)$ & 1339 (34.1) \\
\hline Leptospirosis & $106(21.5)$ & $79(16.1)$ & $131(26.6)$ & $116(23.6)$ & $60(12.2)$ & $492(12.5)$ \\
\hline Enteric fever & $91(36.3)$ & 30 (11.9) & 55 (21.9) & $46(18.3)$ & $29(11.6)$ & $251(6.4)$ \\
\hline Total & 1037 (26.4) & $853(21.7)$ & $903(23)$ & $687(17.5)$ & 448 (11.4) & $3928(100)$ \\
\hline
\end{tabular}

Figure in parentheses shows the percentage, *Acute diarrheal diseases

\begin{tabular}{|c|c|c|c|c|c|c|}
\hline Diseases & 2009 & 2010 & 2011 & 2012 & 2013 & Total number \\
\hline Dengue & $120(5.8)$ & $204(9.8)$ & $84(4.1)$ & $511(24.6)$ & $1156(55.7)$ & $2075(89.8)$ \\
\hline Malaria & $29(13.7)$ & $60(28.4)$ & $31(14.7)$ & $44(20.9)$ & $47(22.3)$ & $211(9.1)$ \\
\hline Others & 3 (12) & $0(0)$ & $9(36)$ & $12(48)$ & $1(4)$ & $25(1.1)$ \\
\hline Total & $152(6.6)$ & $264(11.4)$ & $124(5.4)$ & $567(24.5)$ & $1204(52.1)$ & $2311(100)$ \\
\hline
\end{tabular}

Figure in parentheses shows the percentage

\begin{tabular}{|c|c|c|c|c|c|c|c|c|c|}
\hline \multirow[t]{2}{*}{ Year } & \multicolumn{3}{|c|}{ Summer versus rainy } & \multicolumn{3}{|c|}{ Summer versus winter } & \multicolumn{3}{|c|}{ Rainy versus winter } \\
\hline & Proportion & $\mathbf{Z}$ & $P$ & Proportion & $\mathbf{Z}$ & $P$ & Proportion & $\mathbf{Z}$ & $P$ \\
\hline 2009 & $30 / 49$ & 6.41 & 0.001 & $30 / 21$ & 4.6 & 0.001 & $49 / 21$ & 13.5 & 0.001 \\
\hline 2010 & $46 / 36$ & 6.4 & 0.001 & $46 / 18$ & 19.7 & 0.001 & $36 / 18$ & 11.5 & 0.001 \\
\hline 2011 & $30 / 38$ & 4 & 0.001 & $30 / 32$ & 1.02 & 0.15 & $38 / 32$ & 2.9 & 0.01 \\
\hline 2012 & $28 / 48$ & 12.7 & 0.001 & $28 / 24$ & 2.59 & 0.004 & $48 / 24$ & 14.63 & 0.001 \\
\hline 2013 & $52 / 26$ & 13.8 & 0.001 & $52 / 22$ & 16.3 & 0.001 & $26 / 22$ & 2.35 & 0.01 \\
\hline
\end{tabular}




\begin{tabular}{|c|c|c|c|c|c|c|c|c|c|}
\hline \multirow[t]{2}{*}{ Year } & \multicolumn{3}{|c|}{ Summer versus rainy } & \multicolumn{3}{|c|}{ Summer versus winter } & \multicolumn{3}{|c|}{ Rainy versus winter } \\
\hline & Proportion & $\mathbf{Z}$ & $P$ & Proportion & Z & $P$ & Proportion & $\mathbf{Z}$ & $P$ \\
\hline 2009 & $44 / 34$ & 3.10 & 0.001 & $44 / 22$ & 7.23 & 0.001 & $34 / 22$ & 4.05 & 0.001 \\
\hline 2010 & $41 / 28$ & 4.3 & 0.001 & $41 / 31$ & 3.48 & 0.001 & $28 / 31$ & 1.06 & 0.15 \\
\hline 2011 & $45 / 21$ & 7.16 & 0.001 & $45 / 34$ & 3.07 & 0.001 & $21 / 34$ & 3.98 & 0.001 \\
\hline 2012 & $54 / 27$ & 6.05 & 0.001 & $54 / 19$ & 8.25 & 0.001 & $27 / 19$ & 3.96 & 0.001 \\
\hline 2013 & $14 / 37$ & 6.99 & 0.001 & $14 / 49$ & 10.38 & 0.001 & $37 / 49$ & 3.11 & 0.001 \\
\hline
\end{tabular}

\begin{tabular}{|c|c|c|c|c|c|c|}
\hline Diseases & 2009 & 2010 & 2011 & 2012 & 2013 & Total number \\
\hline Tuberculosis & $1(1.9)$ & $8(14.8)$ & $2(3.7)$ & $26(48.1)$ & $17(31.5)$ & $54(16.93)$ \\
\hline Pneumonia & $8(16.3)$ & $16(32.7)$ & $6(12.2)$ & $8(16.3)$ & $11(22.5)$ & $49(15.36)$ \\
\hline Chicken pox & $7(14)$ & $10(20)$ & $8(16)$ & $13(26)$ & $12(24)$ & $50(15.67)$ \\
\hline Hepatitis B and hepatitis C & $7(16.3)$ & $1(2.3)$ & $5(11.6)$ & $14(32.6)$ & $16(37.2)$ & $43(13.48)$ \\
\hline Hepatitis A & $10(38.5)$ & $7(27)$ & $6(23)$ & $1(3.8)$ & $2(7.7)$ & $26(8.15)$ \\
\hline $\mathrm{AES}^{*}$ & $1(4.3)$ & $0(0)$ & $5(21.7)$ & $3(13.1)$ & $14(60.9)$ & $23(7.21)$ \\
\hline Dengue & $1(5.6)$ & $1(5.6)$ & $0(0)$ & $1(5.6)$ & $15(83.2)$ & $18(5.64)$ \\
\hline Leptospirosis & $6(35.3)$ & $1(5.9)$ & $5(29.4)$ & $1(5.9)$ & $4(23.5)$ & $17(5.33)$ \\
\hline Rabies & $1(6.3)$ & $4(25)$ & $4(25)$ & $4(25)$ & $3(18.7)$ & $16(5.02)$ \\
\hline$A D D^{* *}$ & $2(11.8)$ & $0(0)$ & $4(23.5)$ & $3(17.6)$ & $8(47.1)$ & $17(5.33)$ \\
\hline $\mathrm{H} 1 \mathrm{~N} 1$ & $2(33.3)$ & $3(50)$ & $1(16.7)$ & $0(0)$ & $0(0$ & $6(1.88)$ \\
\hline Total & $46(14.4)$ & $51(16)$ & $46(14.4)$ & $74(23.2)$ & $102(32)$ & $319(100)$ \\
\hline
\end{tabular}

Figure in parentheses shows the percentage, *Acute encephalitis syndrome, $* *$ Acute diarrheal diseases

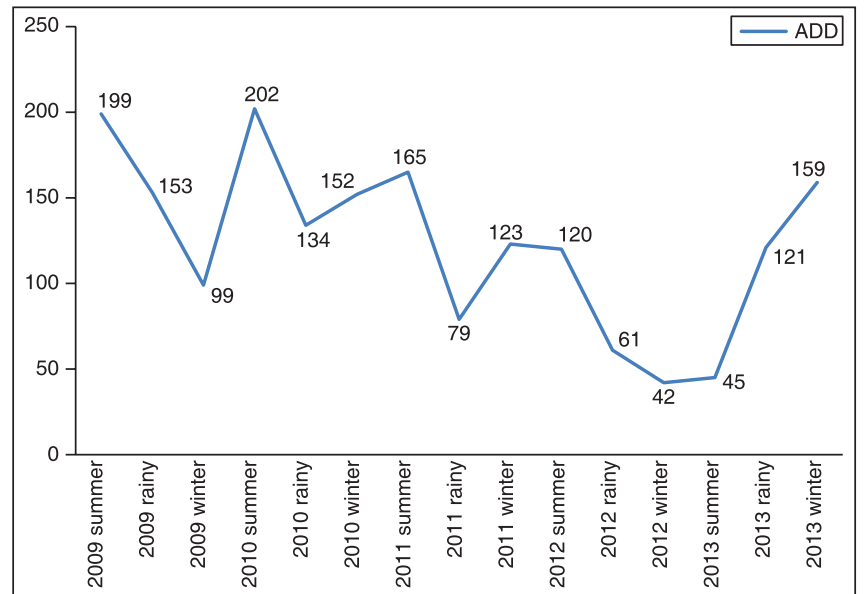

Graph 3: Seasonal variation of acute diarrheal diseases 2009-2013

Like morbidity, higher proportion of mortality was also contributed by air borne diseases (48\%). Tuberculosis, pneumonia and chickenpox were accounted for this mortality. Hepatitis contributed $21.6 \%$ of total deaths. Of which blood borne hepatitis B and hepatitis $\mathrm{C}$ accounted for $13.5 \%$. Deaths due to AES were $7 \%$ while due dengue, leptospirosis, rabies and ADD were $5 \%$.

Mortality showed an increase in trend from 2011 onwards.

\section{DISCUSSION}

Airborne diseases accounted for the highest morbidity, which is the general pattern observed in Kerala. ${ }^{[4]}$ Among the airborne diseases ARI contributed maximum, and this finding is similar to the finding observed by various studies ${ }^{[5-9]}$ Except for 2009, pulmonary tuberculosis was in the second position in hospital admissions for communicable diseases. This is due to the fact that in our institution Revised National Tuberculosis Control Program Unit was included in the communicable disease surveillance from 2010 onwards. After that Tuberculosis showed increasing trend. Similar increasing trend is shown for tuberculosis by Health Status Indicator-2012. ${ }^{[7]}$ Chicken pox cases were reported throughout the 5 years period. However, regarding the magnitude of the disease this is not the actual situation in the district because most of the chicken pox cases receive outpatient treatment, and many people depend on other systems of medicine.

Climatic change with intermittent rain provides a favorable environment for vector breeding, and this accounted for the increase in vector borne diseases. The increase in awareness of living condition and good sanitation might have resulted in a decrease in water borne diseases. The increase in the incidence of other diseases is due to the inclusion of probable cases of dengue, leptospirosis, many of which were lab negative but clinically suggestive.

Incidence ADD was the highest among water borne diseases and it shows a decreasing trend over the years. The proportion of ADD observed is lower when compared to IDSP data. ${ }^{[4]}$ This is because in IDSP data outpatient cases are also included. Hepatitis (Water borne) and leptospirosis are also a public health problems in our state and the present study also shows uniform proportion of these two diseases. ${ }^{[10,11]}$ Not much published data is available on these communicable diseases in the state.

Dengue fever is a major public health problem in the entire state which is observed in the present study also as evidenced by the 
increase in the incidence from the year 2012. This finding is similar to the findings in the National Health Profile-2011. ${ }^{[6]}$ Important causes for this increased trend of dengue are population migration, fast urbanization and increase in constructions in our state providing the conducive environment for vector breeding.

Morbidities due to clustering of communicable diseases are known to follow a seasonal trend. On analysis for seasonal variation ARI showed increase during rainy season, which is the pattern shown in the entire state. However, the pattern of increase in ARI observed in the study conducted by Sharma et al. was during winter. ${ }^{[5]}$

Similarly ADD showed increased incidence during summer, except for the year 2013. This is because during summer, there is scarcity of water and people are forced to use available water distributed through tankers, with more chance of contamination. This occurrence of increased ADD cases during summer is concordant with many other studies. ${ }^{[5,12-14]}$ However, few studies show increase incidence of ADD during winter months. ${ }^{[15,16]}$

The maximum mortality in communicable diseases is due to air borne diseases for the 5 years period in our institution. This finding is similar to the study result of Sharma et al. ${ }^{[5]}$ and also with the National Health Profile 2012. ${ }^{[8]}$

\section{REFERENCES}

1. Council for International Organizations of Medical Sciences. Communicable Diseases, Provisional International Nomenclature. Geneva: World Health Organization; 1973.

2. Detels R, Mceven J, Beag R, Tanaka H. Oxford Text Book of Public Health. $4^{\text {th }}$ ed. New York: Oxford University Press; 2002. p. 172.

3. Kishore J. National Health Programmes of India. $4^{\text {th }}$ ed. New Delhi: Century Publications; 2002. p. 148.

4. Integrated Disease Surveillance Project Epidemiological Situation of Communicable Diseases in Kerala (2006-2010). State Surveillance Unit, Directorate of Health Service, Govt. of Kerala, Thiruvananthapuam. Available from: http://www.dhs.kerala.gov.in/docs/part1.pdf [Last accessed on 2014 Aug 18].

5. Sharma MK, Goel NK, Swami HM, Kumar D. Surveillance of communicable disease at a tertiary care hospital a tool for planning. Indian J Prev Soc Med 2005;36:3-4.

6. Central Bureau of Health Intelligence-India. National Health Profile of India; 2009. Available from: http://www.cbhidghs.nic.in. [Last accessed on 2014 Aug 12].

7. Central Bureau of Health Intelligence-India. National Health Profile of India; 2011. Available from: http://www.cbhidghs.nic.in. [Last accessed on 2014 Aug 12]

8. Central Bureau of Health Intelligence-India. National Health Profile of India; 2012. Available from: http://www.cbhidghs.nic.in. [Last accessed on 2014 Aug 12].

9. Central Bureau of Health Intelligence-India. National Health Profile of India; 2013. Available from: http://www.cbhidghs.nic.in. [Last accessed on 2014 Aug 12].

10. Kumar SS. Indian Guidelines for the Diagnosis and Management of Human Leptospirosis. APICON, Medicine Update. Ch. 7, 2013; p.23-29. www.apiindia.org. [Last accessed on 2014 Aug 18].

11. Report of the Working Group on Disease Burden for the $12^{\text {th }}$ Five Year Plan. WG-3(1): Communicable Diseases. Report (30.7.2011) No.2(6) 2010-H\&FW Govt. of India Planning Commission.

12. Ahmed SF, Farheen A, Muzaffar A, Mattoo GM. Prevalence of diarrhoeal disease, its seasonal and age variation in under- fives in Kashmir, India. Int J Health Sci (Qassim) 2008:2:126-33.

13. Banerjee B, Hazra S, Bandyopadhyay D. Diarrhea management among under fives. Indian Pediatr 2004;41:255-60.

14. El-Gilany AH, Hammad S. Epidemiology of diarrhoeal diseases among children under age 5 years in Dakahlia, Egypt. East Mediterr Health $\mathrm{J}$ 2005; $11: 762-75$

15. Ujwala UU, Shekhar SR, Ganesh SL, Sandeep DS, Nanda NT, Kumar R. Seasonal patterns in acute gastroenteritis in a hospital at Maharashtra. India Int J Health Sci Res 2012;1:101-8.

16. Ananthan S, Saravanan P. Genomic diversity of group A rotavirus RNA from children with acute diarrhoea in Chennai, south India. Indian J Med Res 2000;111:50-6.

How to cite this article: Manjula VD, Bhaskar A, Sobha A. Surveillance of communicable disease from a tertiary care teaching hospital of central Kerala, India. Int J Med Public Health 2015;5:317-21.

Source of Support: Nil, Conflicts of Interest: None declared. 